(c) American Dairy Science Association, 2006.

\title{
Genetic Parameters for Functional Traits in Dairy Cattle from Daily Random Regression Models
}

\author{
B. Karacaören, ${ }^{\star 1}$ F. Jaffrézic, $†$ and H. N. Kadarmideen* \\ *Statistical Animal Genetics Group, Institute of Animal Science, Swiss Federal Institute of Technology, \\ ETH Centrum, Zurich $\mathrm{CH}$ 8092, Switzerland \\ †INRA Quantitative and Applied Genetics, 78352 Jouy-en-Josas Cedex, France
}

\begin{abstract}
The objective of the research was to estimate genetic parameters, such as heritabilities and genetic correlations, using daily test day data for milk yield (MY), milking speed (MS), dry matter intake (DMI), and body weight (BW) using random regression methodology. Data were from first lactation dairy cows $(n=320)$ from the Chamau research farm of the Swiss Federal Institute of Technology, Switzerland over the period from April 1994 to 2004. All traits were recorded daily using automated machines. Estimated heritabilities $\left(\mathrm{h}^{2}\right)$ varied from 0.18 to $0.30\left(\right.$ mean $\mathrm{h}^{2}=0.24$ ) for MY, 0.003 to 0.098 (mean $\mathrm{h}^{2}=0.03$ ) for $\mathrm{MS}, 0.22$ to 0.53 $\left(\right.$ mean $\left.\mathrm{h}^{2}=0.43\right)$ for $\mathrm{BW}$, and 0.12 to $0.34\left(\right.$ mean $\mathrm{h}^{2}=$ 0.23 ) for DMI. A permanent environmental effect was included in both the univariate and bivariate models, but was assumed constant in estimating some genetic correlations because of convergence problems. Estimated genetic correlations varied from 0.31 to 0.41 between MY and MS, from -0.47 to 0.29 between MY and DMI, from -0.60 to 0.54 between $\mathrm{MY}$ and BW, from 0.17 to 0.26 between MS and DMI, from -0.18 to 0.25 between MS and BW, and from -0.89 to 0.29 between DMI and BW. Genetic correlations for MY, MS, DMI, and BW from calving to midlactation decreased similarly to $0.40,0.36,0.14$, and 0.36 and, at the end of the lactation, decreased to $-0.06,0.23,-0.07$, and 0.09 , respectively. Daily genetic variance-covariance of many functional traits are reported for the first time and will be useful when constructing selection indexes for more than one trait based on longitudinal genetic parameters.
\end{abstract}

Key words: functional trait, production trait, genetic parameter, daily random regression model

\section{INTRODUCTION}

Measuring functional traits such as feed intake and BW (especially on a daily basis) is not a common prac-

Received January 19, 2005.

Accepted October 14, 2005.

${ }^{1}$ Corresponding author: burak.karacaoeren@inw.agrl.ethz.ch tice because of the need for expensive labor and equipment. But for milk production, feed costs are the major component of total costs, and literature indicates that there is genetic variation for feed intake and BW (Korver, 1988; Veerkamp, 1998). In addition, feed intake is correlated with other biological functions such as maintenance, growth, reproduction, fetal growth, and energy balance (Veerkamp, 1998). Further, BW, DMI, and milk production level together form an important cluster of functional traits that affect energy balance or its indicator trait, BCS (Kadarmideen and Wegmann, 2003). Milking speed (MS) is another functional trait that relates to the incidence of clinical mastitis, labor time, and electrical power (Boettcher et al., 1998; Ilahi and Kadarmideen, 2004). In practice, MS is often measured by subjective scoring, whereas in the present study, it was measured electronically. Based on the foregoing literature estimates, it could be claimed that under the assumptions of additive genetic infinitesimal model, there should be genetic relationships among MS, DMI, and BW. If there is a genetic relationship, these genetic correlations may change over DIM because these traits are related to each other according to the mean lactation curve. There have not yet been published estimates of how genetic correlations of MS with DMI or BW change over DIM, which could be useful information to clarify the physiological relationships across lactation stages and to construct selection indexes concerning more than one trait across DIM.

Longitudinal data consist of repeated observations across time for different subjects and allow the investigation of time-dependent fixed and random effects. Random regression methodology (Schaeffer and Dekkers, 1994; Jakobsen et al., 2002) has been extensively used for analyzing longitudinal measurements, such as test day yields. The benefits of test day models and analyzing test day yields by random regression methodology have been thoroughly discussed (Swalve, 2000; Jensen, 2001).

In recent years, there has been increased emphasis on estimating genetic parameters for not only production traits but also many health, fertility, feed efficiency, survival, and body condition traits for use in optimized 
selection indexes in dairy cattle (Kadarmideen, 2004). To construct selection indexes for multitrait selection, genetic correlations are needed. Conventional selection indexes use genetic correlations estimated by 305-d lactation-based models (Kadarmideen and Simm, 2002), but this may change in the future to include test dayspecific genetic correlations. Persistency allows the dynamic genetic evaluation of milk yield (MY) to be included in selection indexes. Although it is not known how to introduce such DIM-based information for functional traits into selection indexes, derivation of nonmarket values of functional traits for selection indexes was proposed recently by Nielsen et al. (2005). There are only very few studies that have investigated the traits we chose to analyze here. The objective of this research was to estimate the functions of genetic parameters, such as heritabilities and genetic correlations, for longitudinal data for MY, MS, DMI, and BW using daily test day random regression methodology. Genetic correlations are estimated on a daily basis between these different functional traits and for the same trait over different stages of lactation.

\section{MATERIALS AND METHODS}

\section{Data}

Data were obtained from first lactation records of dairy cows stationed at the Chamau research farm of the Swiss Federal Institute of Technology, Switzerland over the period from April 1994 to 2004. The experimental procedures of the farm followed the Swiss Law on Animal Protection and were approved by the Committee for the Permission of Animal Experiments of the Canton of Zug, Zug, Switzerland. Traits (MY, MS, roughage and concentrate intake, and BW) were recorded daily using automated units by METATRON (American Calan Inc., Northwood, NH). The animals were housed in a free-stall barn. Milk production and other traits were measured 2 times (morning and evening) daily. The concentrate, roughage, minerals, and vitamins were fed according to calculated needs (NRC, 1989).

Data sets were created as follows. A minimum of 60 DIM and $5 \mathrm{~kg}$ of MY were required (Table 1). To estimate genetic correlations, data sets were created with the same times of measurement for all traits involved in bivariate analyses. The DMI was calculated by summing the concentrate and roughage intake. The sum of morning and evening measurements of milk production data per day was used for the analysis of MY and DMI; however, for MS and BW, the measurements were averaged. The pedigree file included 320 cows from 109 sires and 208 dams.

\section{Statistical Models and Analyses}

Analyses. The program ASREML (Gilmour et al., 2001) was used to estimate variance components. Results of the phenotypic analyses were used as starting values in the genetic analyses to estimate variance components using an Average Information (AI-REML) algorithm as implemented in ASREML (Gilmour et al., 2001). A fifth order orthogonal polynomial was chosen for the fixed part of the model, and quadratic random regressions were fitted based on the preliminary analysis and work of Olori et al. (1999) and Coffey et al. (2001). The same fixed effects were fitted for all traits and are given in Model 1.

Univariate Random Regression Model. For each trait, individual deviations from the mean lactation curve were fitted for additive genetic effects using the random regression methodology. The animal model fitted was as follows:

$$
y_{\text {tif }}=\sum_{l=0}^{5} \alpha_{l} v_{t l}+b_{i}+f+\sum_{l=0}^{2} \mu_{t l} a_{j l}+\sum_{l=0}^{2} \mu_{t l} p_{j l}+e_{t i j}
$$

where $y_{t i f}$ is MY (or MS, DMI, BW) produced by cow $j$ on day $t ; \alpha_{l}$ are the fixed regression coefficients, $v$ is the vector of the first 5 polynomials for day $t$ in milk; $b_{i}$ is the fixed breed effect $\left(b_{1}=\right.$ Holstein-Friesian, $n_{1}=206$; $b_{2}=$ Jersey, $n_{2}=54 ; b_{3}=$ Brown Swiss, $n_{3}=42 ; b_{4}=$ Simmental, $n_{4}=12 ; b_{5}=$ Ayrshire, $n_{5}=6$ ); and $f$ consists of other fixed effects including year at calving, season, age at calving (in months), year-season, and DIM-breed interactions. Terms $a_{j l}$ and $p_{j l}$ are random regression coefficients for the additive genetic effects and permanent environmental effects, respectively; $\mu_{t}$ is the vector of the 3 first orthogonal polynomial coefficients for day $t$; and $e_{t i j}$ is the random residual variance assumed to vary by month. Approximate standard errors (ASE) of the heritabilities were estimated monthly across the lactation (Fischer et al., 2004).

Bivariate Random Regression Model. To estimate genetic correlations between 2 traits as a function of time, the following bivariate animal model was used:

$$
\mathrm{y}=\mathbf{X} \mathrm{b}+\mathbf{Z a}+\mathbf{Z} \mathrm{p}+\mathrm{e}
$$

where y contains the observations for the traits specified in Model 1; b are the fixed effects, and a and $\mathrm{p}$ are the set of random regression coefficients for all animals for the additive genetic effects and permanent environmental effects, respectively. Matrices $\mathbf{X}$ and $\mathbf{Z}$ are incidence matrices, and $\mathbf{e}$ is a vector containing environmental effects and residuals. The same fixed effects were fitted for all traits as given in Model 1. For the random effects, it is assumed that 
Table 1. Number of records, means, and standard errors for milk yield (MY), milking speed (MS), BW, and DMI for some selected days of first lactation

\begin{tabular}{|c|c|c|c|c|c|c|c|c|c|c|c|c|}
\hline \multirow[b]{2}{*}{ DIM } & \multicolumn{3}{|c|}{ MY (kg) } & \multicolumn{3}{|c|}{ MS (kg/min) } & \multicolumn{3}{|c|}{ BW (kg) } & \multicolumn{3}{|c|}{ DMI (kg) } \\
\hline & $\mathrm{n}$ & $\overline{\mathrm{X}}$ & $\mathrm{SE}$ & $\mathrm{n}$ & $\overline{\mathrm{X}}$ & SE & $\mathrm{n}$ & $\overline{\mathrm{X}}$ & $\mathrm{SE}$ & $\mathrm{n}$ & $\overline{\mathrm{X}}$ & $\mathrm{SE}$ \\
\hline 5 & 277 & 18.13 & 5.58 & 277 & 18.13 & 0.62 & 246 & 326.33 & 210.38 & 320 & 12.03 & 4.62 \\
\hline 30 & 277 & 21.66 & 6.6 & 277 & 21.66 & 0.8 & 246 & 528.28 & & 320 & 14.67 & 5.41 \\
\hline 60 & 277 & 20.21 & 7.85 & 277 & 20.21 & 0.73 & 246 & 548.93 & 100.8 & 320 & 16.24 & 6.62 \\
\hline 90 & 268 & 18.45 & 7.07 & 268 & 18.45 & 0.73 & 227 & 548.57 & 99.87 & 305 & 15.47 & 5.81 \\
\hline 120 & 257 & 16.93 & 6.51 & 257 & 16.93 & 0.86 & 196 & 552.01 & 104.78 & 289 & 16.03 & 5.34 \\
\hline 150 & 247 & 16.2 & 5.75 & 247 & 16.24 & 0.7 & 18 & 540.15 & 108.17 & 284 & 17.22 & 5.2 \\
\hline 180 & 238 & 14.66 & 5.11 & 238 & 14.66 & 0.68 & 163 & 527.10 & 106. & 276 & 17.93 & 4.92 \\
\hline 210 & 232 & 13.54 & 4.92 & 232 & 13.54 & 0.64 & 157 & 518.86 & 104.05 & 271 & 18.03 & 4.36 \\
\hline 240 & 220 & 12.77 & 4.59 & 220 & 12.77 & 0.62 & 147 & 507.17 & 102.69 & 263 & 17.51 & 5.28 \\
\hline 270 & 190 & 11.66 & 4.10 & 190 & 11.66 & 0.60 & 144 & 506.01 & 104.35 & 259 & 16.37 & 5.19 \\
\hline 305 & 111 & 11.22 & 3.55 & 111 & 11.22 & 0.53 & 137 & 504.51 & 108.57 & 254 & 16.36 & 5.57 \\
\hline
\end{tabular}

$$
\operatorname{Var}\left(\begin{array}{l}
\mathbf{a} \\
\mathbf{p} \\
\mathbf{e}
\end{array}\right) \sim N\left[\mathbf{0} ;\left(\begin{array}{cccc}
\mathbf{G} \otimes \mathbf{A} & \mathbf{0} & \mathbf{0} \\
\mathbf{0} & \mathbf{P} \otimes \mathbf{I} & \mathbf{0} \\
\mathbf{0} & \mathbf{0} & \mathbf{R}
\end{array}\right)\right],
$$

where $\mathbf{G}$ and $\mathbf{P}$ are covariance matrix of the random regression coefficients; $\mathbf{A}$ is the additive genetic relationship matrix for the animals; $\mathbf{I}$ is an identity matrix; $\mathbf{R}$ is a diagonal matrix of the form $\mathbf{I} \sigma_{e}^{2}$, and $\sigma_{e}^{2}$ is the residual variance.

\section{RESULTS AND DISCUSSION}

The means of MY, MS, DMI, and BW were $17.16 \mathrm{~kg} /$ $\mathrm{d}, 1.94 \mathrm{~kg} / \mathrm{min}, 17.42 \mathrm{~kg} / \mathrm{d}$, and $545.12 \mathrm{~kg}$, respectively, and descriptive statistics for MY, MS, DMI, and BW are given in Table 1 for some example DIM.

Because increasing the sampling size for each individual increases the accuracy of parameter estimates (Karacaören, 2001), it could be expected that using daily test day data may provide more accurate parameter estimations compared with, for example, monthly test day data. In the present study, increased accuracy from having daily observations on each animal compensated for a loss in accuracy from smaller total sampling size, which is a typical constraint with data from an experimental farm. The ASE of heritabilities (Table 2) over DIM were found to be relatively higher for BW than the other traits probably because of smaller sampling size compared with other traits (data not shown). Because these data were obtained from an experimental farm, results could not be directly compared with the results of field data sets.

\section{Heritabilities}

Range of estimated heritabilities are provided in Table 2. Ranges were based on daily records from 1 to 305 d. Estimates varied from 0.18 to $0.30\left(\right.$ mean $\left.h^{2}=0.24\right)$ for MY, from 0.003 to $0.098\left(\right.$ mean $\mathrm{h}^{2}=0.03$ ) for MS, from 0.22 to $0.53\left(\right.$ mean $h^{2}=0.43$ ) for $\mathrm{BW}$, and from 0.12 to $0.34\left(\right.$ mean $\mathrm{h}^{2}=0.23$ ) for DMI. Curves drawn using estimated daily heritabilities for MY, MS, DMI, and BW over DIM are presented in Figure 1.

Druet et al. (2003) found the heritability for MY ranged from 0.16 to 0.39 using a random regression test day model from field data. Strabel and Misztal (1999) found a slighlty lower heritability, in the range of 0.13 to 0.17 , and explained that this was because of the low production levels. Olori et al. (1999) found a heritability of 0.41 to 0.52 . Jamrozik and Schaeffer (1997) found heritabilities ranging from 0.40 to 0.59 , predicted the highest heritability during the first $10 \mathrm{~d}$ of lactation, and credited the result to properly accounting for DIM within test days in the random regression model. In the present study, we found the heritability to be highest in the beginning of the lactation (Figure 1), as was found by Jamrozik and Schaeffer (1997). Estimated error variances for MY decreased through the end of the lactation (Table 3 ) as expected but were found to have a relatively different shape and magni-

Table 2. Ranges of daily estimated heritabilities (on diagonal) and daily genetic correlations (below diagonal) among milk yield (MY; $\mathrm{kg})$, milking speed (MS; kg/min), DMI (kg), and BW (kg)

\begin{tabular}{lrlll}
\hline & MY & MS & BW & DMI \\
\hline MY & $0.18-0.30^{1}$ & & & \\
MS & $0.31-0.41$ & $0.003-0.098^{2}$ & & \\
BW & $-0.60-0.54$ & $-0.18-0.25$ & $0.22-0.53^{3}$ & \\
DMI & $-0.47-0.29$ & $0.17-0.26$ & $-0.89-0.29$ & $0.12-0.34^{4}$ \\
\hline
\end{tabular}

\footnotetext{
${ }^{1}$ Average of the range is 0.24 ; approximate standard error ranges from 0.10 to 0.16 .

${ }^{2}$ Average of the range is 0.03 ; approximate standard error ranges from 0.04 to 0.13 .

${ }^{3}$ Average of the range is 0.43 ; approximate standard error ranges from 0.17 to 0.20 .

${ }^{4}$ Average of the range is 0.23 ; approximate standard error ranges from 0.11 to 0.21 .
} 

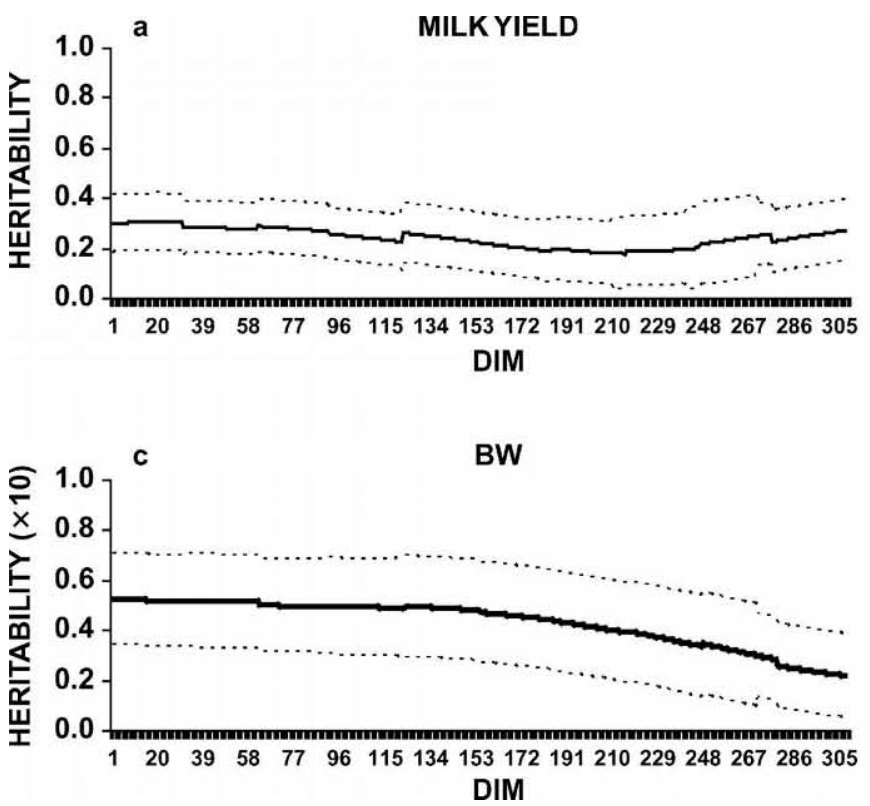
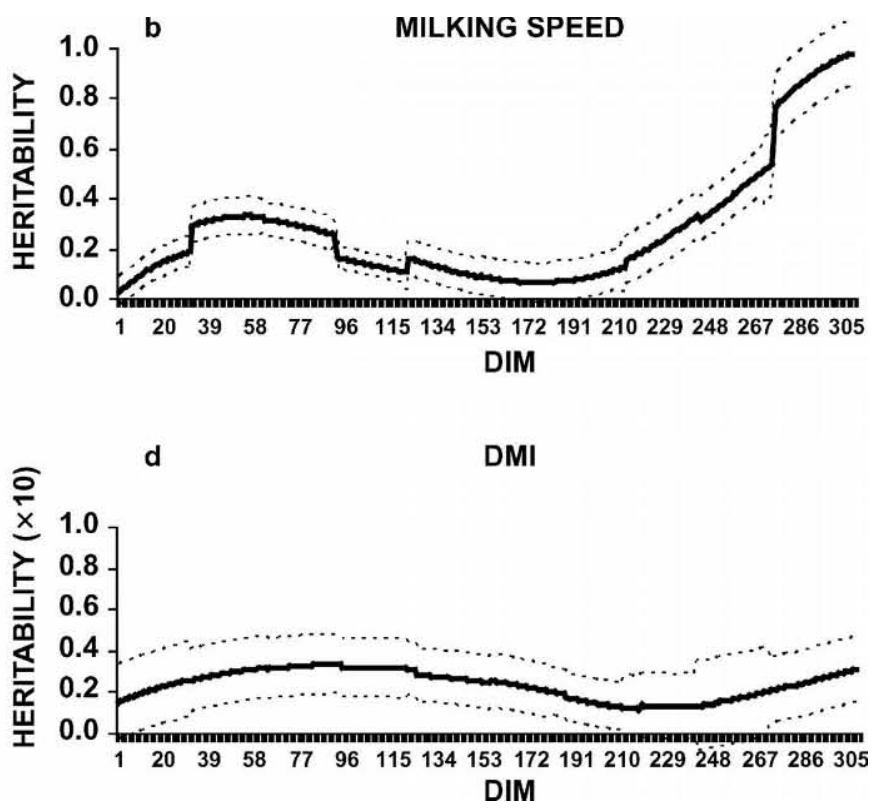

Figure 1. Estimated heritabilities for DIM \pm SE for a) milk yield (kg), b) milking speed (kg/min), c) BW (kg), and d) DMI (kg).

tude than the literature estimates (Olori et al., 1999). The ASE of the heritability for MY (0.10 to 0.16) peaked around 270 DIM to 0.16 then it dropped to 0.12 at 305 DIM.

Genetic parameter estimates for traits such as MS, DMI, or BW were mostly estimated from experimental farm data sets with small sample sizes (Korver, 1988; Van Elzakker and Van Arendonk 1993; Veerkamp, 1998). Therefore, because of the sampling errors, it is hard to expect that there will be a close agreement between the estimates.

Estimates of heritability for MS were found to be around 0.03 (ranging from 0.003 to 0.098); Boettcher et al. (1998) found 0.14, Rupp and Boichard (1999) found 0.17, and Ilahi and Kadarmideen (2004) found 0.25 . However, these results were obtained from subjective scoring (cross-sectional observations) of field data;

Table 3. Residual error variances for milk yield (MY; kg), milking speed (MS; kg/min), DMI ( $\mathrm{kg})$, and BW ( $\mathrm{kg})$ for each measurement error class

\begin{tabular}{rrlrl}
\hline DIM & \multicolumn{1}{c}{ MY } & MS & \multicolumn{1}{l}{ BW } & DMI \\
\hline $1-30$ & 7.97 & 0.50 & 102.28 & 2.97 \\
$31-60$ & 11.26 & 0.24 & 84.96 & 3.12 \\
$61-90$ & 8.90 & 0.26 & 138.13 & 3.32 \\
$91-120$ & 9.61 & 0.56 & 142.27 & 3.81 \\
$121-150$ & 5.33 & 0.26 & 112.82 & 4.63 \\
$151-180$ & 5.86 & 0.23 & 139.78 & 4.28 \\
$181-210$ & 4.60 & 0.20 & 156.12 & 4.91 \\
$211-240$ & 3.48 & 0.13 & 113.63 & 3.83 \\
$241-270$ & 2.38 & 0.16 & 27.67 & 3.57 \\
$271-305$ & 5.19 & 0.05 & 314.51 & 3.94 \\
\hline
\end{tabular}

whereas in the present study, MS was measured electronically and daily over DIM. Zwald et al. (2005) found the heritability of 0.17 using objectively and weekly measured field data and a sire model with Bayesian methodology, which is closer to the results of subjectively measured studies; likely, the number of animals and differences that could be observed under certain longitudinal settings when using sire and animal models explain the differences in the estimated heritabilities between the present study and the others. Error variances for MS also decreased throughout lactation, but there was a peak around 150 DIM (Table 3). The ASE of heritabilities for MS tended to increase throughout lactation.

We averaged morning and evening measurements to estimate the heritability for BW (ranging between 0.22 and 0.53 , mean $\mathrm{h}^{2}=0.43$ ). Veerkamp (1998) noted that heritability estimates are generally high, especially when weight is based on the average of more than one measurement. Veerkamp et al. (2000) found the heritability for the first $15 \mathrm{wk}$ equal to 0.61 using a random regression model, whereas we estimated the heritability as 0.51 for this period. Other literature estimates were obtained with multitrait analyses; Tveit et al. (1991) found 0.65, and Svendsen et al. (1994) found 0.64 . The shape of the estimated heritability curve over DIM of BW (Figure 1) shows increase and decrease, respectively, as cows were fed according to their yield. Error variances for BW increased to around $50 \mathrm{~kg}^{2}$ at d 270 and then further increased to $300 \mathrm{~kg}^{2}$ at d 300 (Table 3). The ASE of heritability for BW was found to 
be stable across DIM, but a small decline was observed (at 270 to 305 DIM as 0.20 to 0.17 ) at the end of the lactation.

Hooven et al. (1968) found the heritability for DMI equal to 0.38 using 318 cows with a multitrait model, whereas we found 0.23 (ranging from 0.12 to 0.34 ). Based on data from 628 heifers for the first 15 wk of lactation and using a random regression model, Veerkamp and Thompson (1999) found the heritability equal to 0.30 . In the present study, it was estimated to be 0.29 for that period. Lee et al. (1992) found the heritability equal to 0.27 for wk 26 to 34 of the lactation, whereas we estimated it to be 0.15 for that period of lactation. The differences concerning the number of animals, measurement stage of lactation, feeding regimen, and statistical methodology between various studies explains the differences obtained for the heritability estimates for DMI (Van Arendonk et al., 1991). Estimated heritabilities over DIM for DMI increased (Figure 1) toward the end of the lactation. Error variances and ASE of heritability for DMI showed no systematic pattern (Table 3).

\section{Longitudinal Genetic Correlations}

Because genetic correlations were obtained using random regression methodology, results could be useful to change genetic patterns through selection using multitrait selection indexes. Longitudinal genetic correlations for many functional traits reported here were one of the main contributions of this study, as very few studies have reported genetic correlations from a multivariate daily random regression model (Coffey et al., 2001; Jakobsen et al., 2002; Berry et al., 2003). However, because of the convergence problems for estimating genetic correlations of MY-DMI and BW-DMI, a permanent environmental effect had to be assumed constant. In addition, some of the parameter estimates from bivariate combinations were found to be at boundary values of the parameter space.

Genetic Correlations between Beginning, Mid, and End of the Lactation within Traits. Genetic correlations for MY, MS, DMI, and BW at calving to midlactation monotonically decreased to $0.40,0.36$, 0.14 , and 0.36 , respectively, and at the end of the lactation, decreased to $-0.06,0.23,-0.07$ and 0.09 , respectively (Figure 2).

For MY, the genetic correlation between $\mathrm{d} 1$ and 247 was estimated to be 0.03 , which is smaller than the estimate of Coffey et al. (2001). Conversely, genetic correlations of MS between adjacent days decreased less rapidly between beginning and late lactation, and it had the highest genetic correlation between beginning and end of the lactation.

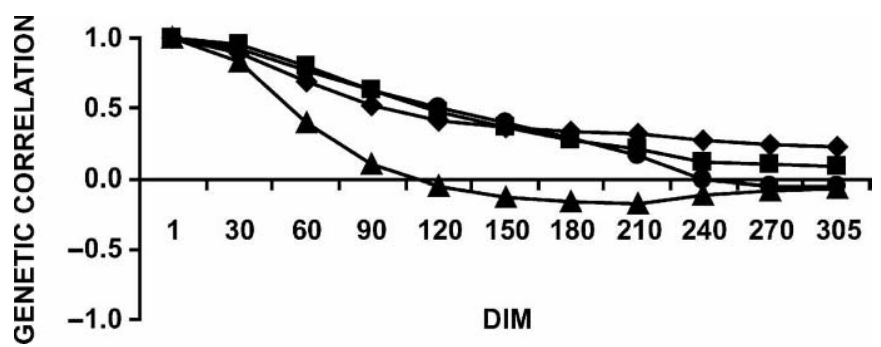

Figure 2. Genetic correlations of functional traits on DIM 1 with

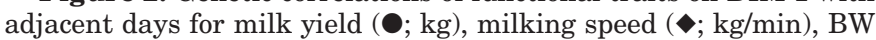
$(\boldsymbol{\square} ; \mathrm{kg})$, and DMI $(\boldsymbol{\Lambda} ; \mathrm{kg})$. Data for every $30 \mathrm{~d}$ are shown.

Genetic correlations of DMI for adjacent days decreased more rapidly compared with the others at the beginning and end of the lactation (Figure 2). We found monotonic decreases followed by slight increases through the end of the lactation, which was different from the shape of the estimates by Coffey et al. (2001).

For adjacent days, highest genetic correlations were obtained for MS, followed by BW. But BW correlations were still smaller than the estimates of Veerkamp and Thompson (1999) and Coffey et al. (2001).

Genetic Correlations between Milk Yield and Functional Traits. The ranges of estimated genetic correlations are provided in Table 2. The curves of the estimated genetic correlations among MY, MS, DMI, and BW over the entire lactation are shown in Figure 3 . Although for some part of the lactation, genetic correlations were high, the small amount of data suggests that results should still be interpreted carefully and confirmed in different dairy cattle populations to determine whether the estimated relationships are of correct magnitude.

Our results indicated that there is a moderate mean genetic correlation among MY and MS $\left(\bar{r}_{g}=0.36\right)$ that ranged from 0.31 to 0.41 . The genetic correlation slightly increased throughout the lactation. This can be explained by the fact that, MY is low at the end of the lactation; hence, the MS is increased (or milking time is also decreased) according to the mean lactation curve.

Genetic correlations changed from being positive to being negative around d 159 for MY and BW (Figure 3 ) and ranged from -0.60 to 0.54. Veerkamp and Brotherstone (1997) explained that this phenomenon happens because body fat and BW are closely related during some part of the lactation (genetic correlation from 0.27 to 0.67 ).

Estimated genetic correlations among MY and DMI ranged from -0.47 to 0.29 . We found the correlations changed from negative to positive at $d$ 84. Veerkamp (1998) concluded that estimated genetic correlations 


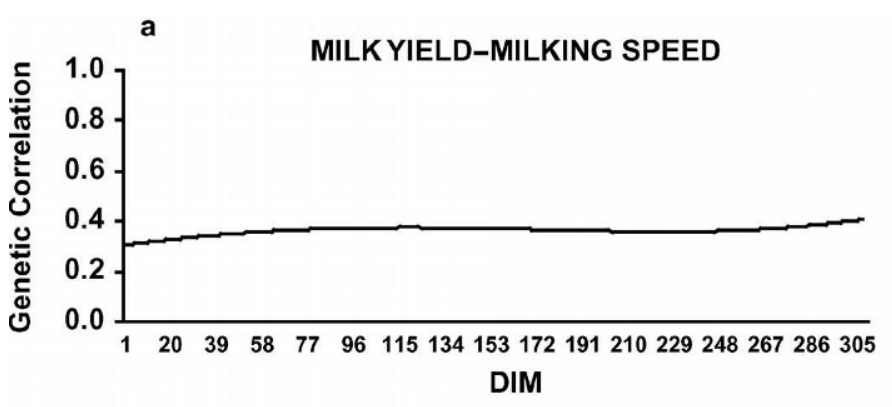

c
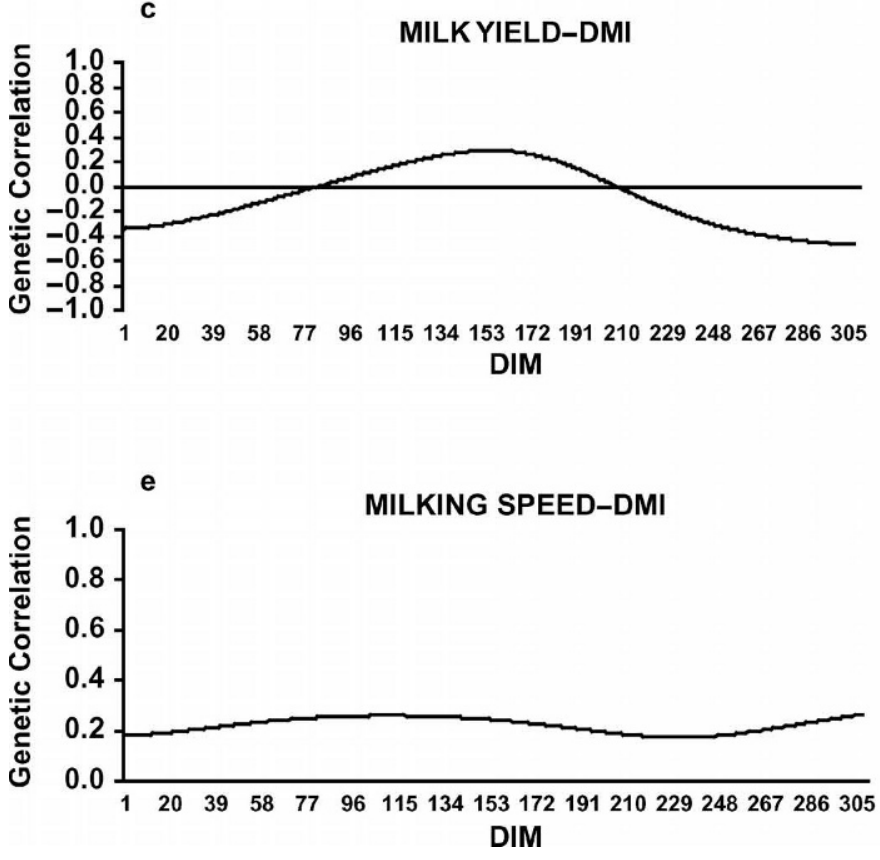
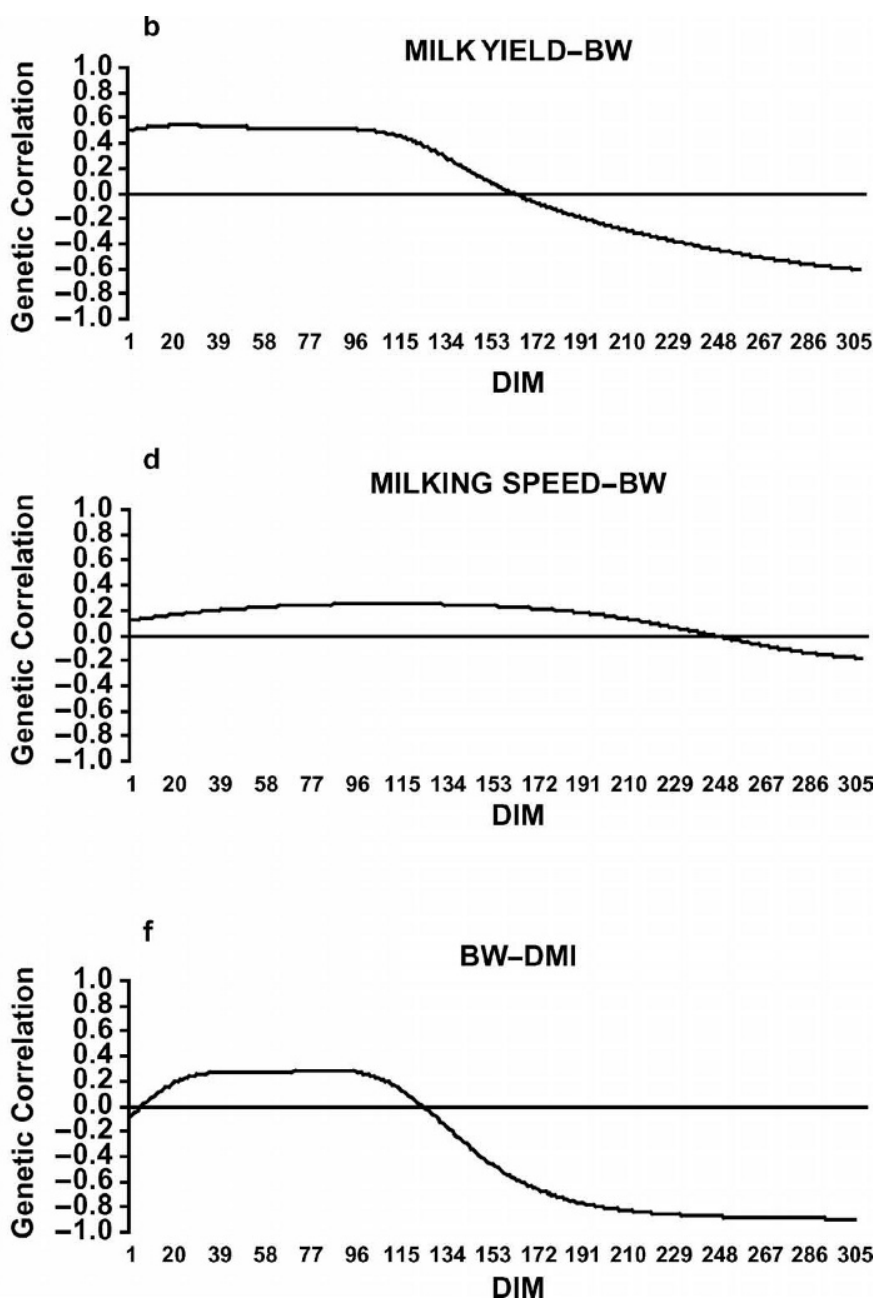

Figure 3. Genetic correlations between a) milk yield ( $\mathrm{kg}$ ) and milking speed ( $\mathrm{kg} / \mathrm{min}) \mathrm{b}$ ) milk yield (kg) and BW (kg), c) milk yield (kg) and DMI (kg), d) milking speed (kg/d) and BW (kg), e) milking speed (kg/d) and DMI (kg), and f) BW (kg) and DMI (kg).

outside of the range 0.46 to 0.65 were artificially high because, especially under experimental conditions, cows were fed according to yield. Additionally, feeding regimen (for example concentrate) is adjusted according to production, which increases the correlation between feed intake and production (Van Arendonk et al., 1991).

Genetic Correlations among Functional Traits. Estimated genetic correlations between MS and BW ranged from -0.18 to 0.25 , and those between MY and BW ranged from -0.60 to 0.54 . Both followed a similar pattern. This is explained by the phenomenon that, toward the end of the lactation, as cows prepare to dry off, they use energy to store body fat for the next calving rather than for milk production (Kadarmideen and Wegmann, 2003), which results in low MY; hence, the genetic correlation curve switches from positive to negative (Figure 3). By analogy, decreasing milk production increases MS (or decreases milking time), and that is related to BW. Estimated genetic correlations between MS and DMI ranged from 0.17 to $0.26\left(\bar{r}_{g}=0.22\right)$.

Genetic correlations between DMI and BW ranged from -0.89 to 0.29; Van Arendonk et al. (1991) found the genetic correlation to be 0.65 , and Veerkamp and Brotherstone (1997) found it to be 0.23 . The genetic correlation between DMI and BW decreased as DIM increased, becoming negative toward the middle of the lactation (Figure 3). This is because feeding regimen is adjusted according to production.

Some of the traits, such as DMI and BW, are not routinely recorded in national cattle populations; others are recorded (MY and MS). The results from this study would still be useful for general cattle populations because longitudinal correlations of MY and MS with DMI and BW provide knowledge about how the physiological or genetic relationships differ with lactation stages. In turn, this can help in placing appropriate weights for 
MY and MS in a national selection index. Such an index may include traits correlated to BW (e.g., BCS) and to DMI (e.g., milk composition traits).

\section{CONCLUSIONS}

This study estimated genetic parameters for daily observations of several functional and production traits and correlations among them over DIM using the random regression methodology. Dairy cattle used were kept under experimental conditions to facilitate data collection. This is one of the very few studies that has investigated estimation of heritabilities and genetic correlations on a daily basis for a variety of functional and production traits. This study also estimated genetic correlations by considering the same trait to be different depending on the stage of lactation. Although, based on experimental data, these results show important patterns of genetic properties and relationships for many traits that are important for national dairy cattle breeding programs. These parameter estimates would be useful to construct selection indexes for more than one functional trait, based on test-day specific genetic correlations, and to change the trajectory of genetic profile or patterns. However, statistics that capture the longitudinal nature of the measurements should be created for functional traits, as is done for MY using persistency, to place the information into selection indexes. Because the sample size was not large (as is typical for data from an experimental farm), results should still be interpreted carefully and confirmed in different cattle populations.

\section{ACKNOWLEDGMENTS}

The authors thank all personnel in the research station of Swiss Federal Institute of Technology in Chamau, Zug, Switzerland, for their help in data collection over a number of years. The authors thank Luc Janss, Kaspar Tschuemperlin, Christian Hagger, Hans Leuenberger, and the anonymous reviewers for useful comments.

\section{REFERENCES}

Berry, D. P., F. Buckley, P. Dillon, R. D. Evans, M. Rath, and R. F. Veerkamp. 2003. Genetic relationships among body condition score, body weight, milk yield and fertility in dairy cows. J. Dairy Sci. 86:2193-2204.

Boettcher, P. J., J. C. M. Dekkers, and B. W. Kolstad. 1998. Development of an udder health index for sire selection based on somatic cell score, udder conformation, and milking speed. J. Dairy Sci. 81:1157-1168.

Coffey, M. P., G. C. Emmans, and S. Brotherstone. 2001. Genetic evaluation of dairy bulls for energy balance traits using random regression. Anim. Sci. 73:29-40.

Druet, T., F. Jaffrézic, D. Boichard, and V. Ducrocq. 2003. Modeling lactation curves and estimation of genetic parameters for first lactation test-day records of French Holstein cows. J. Dairy Sci. $86: 2480-2490$.

Fischer, M. T., A. R. Gilmour, and J. H. J. van der Werf. 2004. Computing approximate standard errors for genetic parameters derived from random regression models fitted by average information REML. Genet. Sel. Evol. 36:363-369.

Gilmour, A. R., B. R. Cullis, S. J. Welham, and R. Thompson. 2001. ASREML Reference Manual. New South Wales Agriculture, Orange Agricultural Institute, Orange, NSW, Australia.

Hooven, N. W., Jr., R. H. Miller, and R. D. Plowman. 1968. Genetic and environmental relationships among efficiency, yield, consumption and weight of Holstein cows. J. Dairy Sci. 51:1409-1419.

Ilahi, H., and H. N. Kadarmideen. 2004. Bayesian segregation analysis of milk flow in Swiss dairy cattle using Gibbs sampling. Genet. Sel. Evol. 36:563-576.

Jakobsen, J. H., P. Madsen, J. Jensen, J. Pedersen, L. G. Christensen, and D. A. Sorensen. 2002. Genetic parameters for milk production and persistency for Danish Holsteins estimated in random regression models using REML. J. Dairy Sci. 85:1607-1616.

Jamrozik, J., and L. R. Schaeffer. 1997. Estimates of genetic parameters for a test-day model with random regressions for yield traits of first lactation Holsteins. J. Dairy Sci. 80:762-770.

Jensen, J. 2001. Genetic evaluation of dairy cattle using test-day models. J. Dairy Sci. 84:2803-2812.

Kadarmideen, H. N. 2004. Genetic correlations among body condition score, somatic cell count, production, reproduction and conformation traits in Swiss Holsteins. Anim. Sci. 79:191-201.

Kadarmideen, H. N., and G. Simm. 2002. Selection responses expected from index selection including disease resistance, fertility and longevity in dairy cattle. Proc. 7th World Congr. Genet. Appl. Livest. Prod. (WCGALP), France. 29:119-122.

Kadarmideen, H. N., and S. Wegmann. 2003. Genetic parameters for body condition score and its relationship with type and production traits in Swiss Holsteins. J. Dairy Sci. 86:3685-3693.

Karacaören, B. 2001. Analysis of univariate selection index using different statistical methods. (In Turkish.) M. S. Thesis, Akdeniz Univ., Turkey.

Korver, S. 1988. Genetic aspects of feed intake and feed efficiency in dairy cattle: Review. Livest. Prod. Sci. 20:1-13.

Lee, A. J., D. A. Boichard, A. J. McAllister, C. Y. Lin, K. Nadarajah, T. R. Batra, G. L. Roy, and J. A. Vesely. 1992. Genetics of growth, feed intake, and milk yield in Holstein cattle. J. Dairy Sci. 75:3145-3154.

Nielsen, H. M., L. G. Christensen, and A. F. Groen. 2005. Derivation of sustainable breeding goals for dairy cattle using selection index theory. J. Dairy Sci. 88:1882-1890.

NRC. 1989. Nutrient Requirements of Dairy Cattle. 6th rev. ed. Natl. Acad. Press, Washington, DC.

Olori, V. E., W. G. Hill, B. J. McGuirk, and S. Brotherstone. 1999. Estimating variance components for test day milk records by restricted maximum likelihood with a random regression animal model. Livest. Prod. Sci. 61:53-63.

Rupp, R., and D. Boichard. 1999. Genetic parameters for clinical mastitis, somatic cell score, production, udder type traits and milking ease in first lactation Holsteins. J. Dairy Sci. 82:21982204.

Schaeffer, L. R., and J. C. M. Dekkers. 1994. Random regressions in animal models for test-day production in dairy cattle. Proc. 5th World Congr. Genet. Appl. Livest. Prod. (WCGALP), Canada 18:443-446.

Strabel, T., and I. Misztal. 1999. Genetic parameters for first and second lactation milk yields of Polish Black and White cattle with random regression test-day models. J. Dairy Sci. 82:2805-2810.

Svendsen, M., P. Skipenes, and I. L. Mao. 1994. Genetic correlations in the feed conversion complex of primiparous cows at a recommended and a reduced plane of nutrition. J. Anim. Sci. $72: 1441-1449$.

Swalve, H. 2000. Theoretical basis and computational methods for different test-day genetic evaluation methods. J. Dairy Sci. 83:1115-1124. 
Tveit, B., M. Svendsen, and K. Hove. 1991. Heritability of hypocalcemia at first parturition in Norwegian cattle: Genetic correlations with yield and weight. J. Dairy Sci. 74:3561-3567.

Van Arendonk, J. A. M., G. J. Nieuwhof, H. Vos, and S. Korver. 1991. Genetic aspects of feed intake and efficiency in lactating dairy heifers. Livest. Prod. Sci. 29:263-275.

Van Elzakker, P. J. M., and J. A. M. Van Arendonk. 1993. Feed intake, body weight and milk production: genetic analysis of different measurements in lactating dairy heifers. Livest. Prod. Sci. $37: 37-51$.

Veerkamp, R. F. 1998. Selection for economic efficiency of dairy cattle using information on live weight and feed intake: A review. J. Dairy Sci. 81:1109-1119.
Veerkamp, R. F., and S. Brotherstone. 1997. Genetic correlations between linear type traits, food intake, live weight and condition score in Holstein Friesian dairy cattle. Anim. Sci. 64:385-392.

Veerkamp, R. F., J. K. Oldenbroek, H. J. Van der Gaast, and J. H. J. Van der Werf. 2000. Genetic correlation between days until start of luteal activity and milk yield, energy balance and live weights. J. Dairy Sci. 83:577-583.

Veerkamp, R. F., and R. Thompson. 1999. A covariance function for feed intake, live weight, and milk yield estimated using a random regression model. J. Dairy Sci. 82:1565-1573.

Zwald, N. R., K. A. Weigel, Y. M. Chang, R. D. Welper, and J. S. Clay. 2005. Genetic evaluation of dairy sires for milking duration using electronically recorded milking times of their daughters. J. Dairy Sci. 88:1192-1198. 